\title{
Transculturalidade e ficções migratórias no cinema da identidade: experiências diaspóricas em 14 Kilómetros
}

\author{
Rafael Tassi Teixeira \\ Doutor em Sociologia (Universidade Complutense de Madrid) \\ Professor doutor da Universidade Tuiuti do Paraná \\ rafaeltassiteixeira@gmail.com
}

O presente trabalho parte de uma interrogação bastante presente nos discursos migratórios contemporâneos: como as narrativas em trânsito reposicionam os sujeitos na condição do olhar sobre a relação foraneidade-autoctonia, pensadas através da experiência fundamental do deslocamento? $\mathrm{O}$ artigo explora as relações entre as escolhas das narrativas e a identidade na estrada, focalizando as dinâmicas interculturais entre as historicidades móveis e as culturas de recepção. Desenvolve a imagem da experiência do deslocamento como condição estrutural da construção dos itinerários culturais a partir de "zonas de contato/emergência" abertas pela globalização circundante, que tem significativo impacto nas dinâmicas da alteridade imigrante. Posteriormente, o trabalho analisa a reflexividade ensaística a partir da emergência do olhar sobre a imagem dos lugares migratórios em relação a um discurso filmico a respeito de imigrantes em processos de trânsito. A relação subjetividade-cultura é pensada através da imagem do migrante em busca da identificação psicológica e comunitária na relativização espacial. As identidades observadas pela cultura de envolvimento e a relação de forças, hegemônicas e assimétricas, servem de material para reflexão do alcance comparativo "Nós-Outros".

Palavras-chave: transculturalidade, narrativas imigrantes, cinema, identidade, cultura. 


\section{Itinerário, transculturalismo, globalização migratória: culturas de absorvência e alteridade imigrante}

A experiência do deslocamento é uma experiência fragmentária, que serve de ponto de encontro com a representação do Outro e, ao mesmo tempo, processo de ligadura da nova identidade em trânsito. O percurso migratório permite que os itinerários transculturais sejam lidos a partir da ideia do contato e a díade recepção-envolvimento tem a ver com a qualidade e a capacidade de negociação dessas transformações. $O$ sentido cultural dessa interpretação está alinhado com a imagem proposta por James Clifford (1977), a partir da ideia dos museus como "zonas de contato". Essa ideia é ponto de inspiração para a imagem que tentaremos explorar das "zonas de contato" como processos de "zonas de emergência" abertas pela globalização circundante que tem a ver com a capacidade cada vez maior dos trânsitos migratórios serem estímulos constantes de reposicionamento identitário na contemporaneidade.

A relação entre a cultura de absorvência e a alteridade imigrante pode ser lida com uma problemática muito discutida no livro de Clifford. As identidades são tecidas nas "zonas de contato", redes de encontros que repercutem como uma primeira ficção do Outro: a capacidade de negociar universos significacionais interpretados pela dinâmica da representação, entendida como jogos simbólicos que nomeiam elementos de significados no universo em trânsito. O nome dessa composição cliffordiana é "transculturalismo", evidência de que os lugares posicionais das identidades não são conjuntos heurísticos de relações, mas pontos estratégicos da possibilidade transformatória da construção das representações das identidades entre culturas de partida e de envolvimento. ${ }^{1}$

Nesse aspecto, o que procuramos explorar aqui é a ideia de que apenas a dimensão do deslocamento imigrante, no jogo de relação Eu-Outro, abre com tanta evidência a possibilidade de uma reflexividade emergente. A utilização do contato como possibilidade transformática está implícita nas novas realidades interculturais abertas pela mobilidade, conferindo os itinerários como "zonas de emergência" da autorrepresentação disponibilizada no espelho do desterramento.

A interculturalidade dispõe uma reflexividade da pertença, e o deslocamento como "zona de contato" cultural refaz a possibilidade autocrítica a partir das histórias de contato. A mobilidade concede uma visão de portabilidade da 'identidade cultural' como propriedade autônoma do discurso representacional. Como indica Clifford (1999) em Dilemas de la cultura: uma maior participação na autonomia representativa preconiza que a identidade é sentida como um artefato, manejável a partir da arbitrariedade das posições deslocadas. Nos termos da transição sujeito-posição de origem e posição de partida, essa perspectiva é em si mesma um processo que pode ser também compreendido pela busca de uma maior sensação de neutralidade na justaposição dos deslocamentos, quando a

1 Robert Cantwell (1993) denomina esse processo de "etnomímese" ou a característica de replicagem da representação da cultura e da tradição a partir da consciência de seu poder identitário. 
mudança territorial abre a possibilidade de novas “zonas de emergência”, que provocam um predomínio da autoimagem a partir da ficção de si.

Nossa ideia é, portanto, deslocar a proposta de Clifford (1977) dos museus como "zonas de contato" e estudar o trânsito migratório contemporâneo em suas identidades emergentes, observando-as como "textos culturais" enredados em processos descontínuos de significação, especificamente no cinema que tem raiz (Van Liew, 2008) nessa busca por um retrato mais fidedigno, ou, ao menos, mais sociologicamente comprometido com a natureza das relações sujeito-identidade-identificação-cultura-mobilidade.

As histórias de vida dos objetos dos museus, analisados por Clifford (1977) dentro da perspectiva dos museus como "artefatos", servem de influência para se pensar o enfoque das representações das identidades quando estiverem em trânsito. Essa relação entre reflexividade crítica e neutralização de discrepâncias representacionais está na dinâmica mesma dos processos de mobilidade migratória. A alteridade imigrante, da mesma maneira que os museus analisados pelo autor, tende a produzir um processo de tradução menos complexo do que se poderia esperar, assim como os textos culturais das narrativas migratórias expostas nos filmes sociologicamente híbridos dos discursos da transposição de fronteiras são, dentro de seus elementos específicos, discursos de convergência e divergência. Não obstante, o deslocamento "escreve" a identidade dentro de uma situação limítrofe, que consegue abrir um novo elemento de negociação dessa identidade, uma vez que as representações passam a ser mediadas pelo imaginário da fronteirização imigrante entre receptores e deslocados.

Se os museus são "zonas de contato", que destacam o exibicionismo das exposições desde a escolha das peças à ideia da representação, as identidades emergentes das migrações, expostas através das narrativas filmicas imigrantes, são, juntas, componentes de uma mesma e mais abrangente percepção da autoimagem exposta pela transição migratória.A noção de interculturalidade nesse jogo de alterações tem a ver com a maneira com que as "zonas de contato" conseguem dialogar entre si, sem perder de vista a descontinuidade ou a fratura das representações.

A proposição de Clifford, como base de referência, é fazer uma leitura das peças dos museus como artefatos que transitam transculturalmente, dando uma imagem de loquacidade que não está diretamente determinada pela ficção de "um sobre o Outro". Desse entendimento, conforme aponta Stocking (1983), os objetos transmutam interculturalmente ao se deslocar, mas também conseguem propor pontes de significados comunicacionais, que explicam a estrutura das percepções a partir de imagens próprias em suas estruturas de referências principais ${ }^{2}$.

A imagem que propomos, seguindo essa dinâmica transcultural, é que as narrativas filmicas imigrantes no cinema contemporâneo (de matriz sociológica e comprometido com a realidade que retrata) são itinerários de identidade e identificação em um jogo de representações que trata da "imaterialidade" da representação para além dos projetos da comunidade de origem e da de absorvência. Assim como os objetos dos museus são

2 E, quando elas inexistem, passam a vigorar a partir de estruturas auxiliares, retiradas de outros lugares, que tendem a explorar reducionismos tópicos extraídos de situações diversas. 
lidos (des)situados das estruturas típicas que dão sentido e coerência em termos de uma historicidade custodiada como pertencentes a certa comunidade de origem, as narrativas filmicas migratórias podem ter um elemento importante de "soltura" biográfica que, menos como lugar de disputa e autoconsagração, se tornam mais a emergência da identidade em um domínio transfronteiriço.

Nessa ideia, os objetos, segundo Clifford (1977), conseguem transpor os limites culturais e dialogar através de representações negociadas no espaço-tempo. De maneira similar, as narrativas do "cinema" "(ins)surgente" (Ballesteros, 2001) são entretecidas por imaginários que as coletivizam, e, de maneira idêntica ao que o objeto impera na instância da percepção transfronteiriça, se o olhar estiver suficientemente distanciado no espaço-tempo, o "texto" ou a voz migratória se torna um elemento de intercomunicabilidade a ser considerado no horizonte das sociedades de abrangência dos imigrantes.

A margem da sensibilidade estética latente para se ler um objeto a partir de referências que não existem na própria cultura é um ponto de discussão importante entre a representação e as formas institucionais dela. Nesse âmbito, as histórias imigrantes nos filmes contemporâneos, com apoio da interculturalidade, se entrecruzam em perspectivas múltiplas que se tornam os discursos de identificação ao narrarem uma cultura de renovação, resistência e ressignificação a partir de olhares que se estabelecem em distâncias diaspóricas. Tomar emprestado de outros lugares a condição da inteligibilidade não é algo absolutamente novo nesses contextos de luta e comunicação entre fronteiras. Mas a noção de procedência do "objeto", de modo similar à noção de "voz" imigrante, tem a ver com aquilo que Clifford chama de uma "centralidade tática" dos objetos ditos "marginais", provenientes da Arte Tribal dentro dos templos de museus tradicionais. Se tais museus, segundo Clifford, são lidos menos como "centro" que como "zona de contato", as vozes narradas pelos imigrantes em deslocamento também podem ser, de algum modo, vistas como espectros de negociação disponíveis a partir do elemento diaspórico e não pela clausura dele.

A articulação possível é avançar e ler os discursos migratórios dos filmes que, seguindo Ballesteros (2001), convencionalmente chamaremos de "(in)surgentes", como "textos" que são abertos pela disposição migratória, concedendo à narrativa uma possibilidade de finalização da identidade possível e desejada pelo entrecruzamento cultural.

A proposta de Clifford (1998, p. 18) é observar os objetos como transcendentes e como "processos históricos não acabados de viagens e cruzamentos", que se alteram conceitualmente a partir da imagem do deslocamento. Os filmes dos textos migratórios "(in) surgentes", portanto, são domínios de referência que forjam suas utilidades nas fronteiras interculturais, entre autorrepresentação e comunicabilidade da situação em trânsito. $\mathrm{O}$ ponto de desigualdade entre a metáfora da representação a partir de si e o conhecimento da identidade em trânsito é enriquecido nesse elemento de "destribalização" da identidade coletiva e na maior possibilidade de autorreferência à identidade biográfica. A comunicação aberta pelo deslocamento torna a voz imigrante uma extensão consideravelmente superior e inacabada do horizonte de domínio situado da especificidade tribal. A identidade gestada no domínio da cultura de absorvência e da alteridade migratória coloca 
a favor do "texto" filmico imigrante uma nova disposição para a perspectiva do contato, que é lida em uma negociação recíproca entre os deslocados e os receptores.

Nesse ponto, a tese principal está vinculada à possibilidade de pensar que as identidades podem ser mais úteis quando devolvidas ao sentido interrelacional constitutivo e provisório que está historicamente longe do estigma da coletividade e, ao mesmo tempo, livre ou aberta para renegociar suas biografias e identificações sem estar necessariamente apreendida pela articulação hegemônica dos interesses da coletividade ${ }^{3}$. Um segundo elemento dessa discussão passa a ser, então, tentar caracterizar como essas vozes, que são com frequência discrepantes e negativamente polarizadas, podem dialogar em estruturas de convergência que correspondem à própria ideia da construção cultural.

De modo imaginado, a questão é pensar a transculturalidade dos objetos e a circulação de seus limites para além das possibilidades mais estacionárias da identidade. Ou, problematizando de outro modo, como disponibilizar tais identidades quando estiverem em trânsito para que consigam promover os aspectos mais colaborativos dentro de limites generosos que não frisem ou não optem preferencialmente pela exibição coletiva em termos de "coletividades", "etnicidades", "nação" e "regionalidades".

Repensando as identidades em trânsito como processos de convergência da globalização migratória, a questão também pode ser colocada em relação a como poder praticar os textos migratórios dos filmes "(in)surgentes” em intercomunicabilidades desvestidas das relações "autêntico" e "não autêntico". Se os objetos, na perspectiva cliffordiana, conseguem transpor culturas e abrir espaço para o valor do "desaldeamento/destribalização" em uma noção maior de comunicação relacional, as múltiplas vozes imigrantes no espaço globalizatório do cinema da representação transfronteiriça apresentam âmbitos de identidades em formação, translocais e transculturais, que, sem perder necessariamente a referência próprio-local, conseguem ampliar suas sensibilidades para além daquilo que Clifford chama de "imobilidade formal" dos objetos dentro dos museus ${ }^{4}$. A identidade em trânsito, como "zonas de contato", amplia a portabilidade de transcendência e de negociação das características do pertencer e abre a possibilidade de ser lida como um procedimento diacrítico inacabado de diferenciação, assinatura e coletividade que, pelo próprio trânsito do anonimato, consegue dialogar com as incorporações mediadas e com (sua) a própria renúncia.

Se o deslocamento abre a possibilidade do exercício de rupturas, forçadas ou não, a identidade em trânsito (e não necessariamente transitória!) consegue fazer a diferenciação cultural longe dos “espessamentos” das instituições em seus âmbitos de, segundo Clifford

3 Clifford (1999,p. 156, tradução minha) faz a crítica a essa construção com a relação entre o domínio do "patrimônio substituindo a história" e "assim contribuindo para a articulação hegemônica dos interesses nacionais e de classe".

4 O olhar do espectador 'complementa' o objeto no museu e lhe dá outro sentido que não o do inscrito ao código cultural indexado. As identidades ou os textos migratórios são também sugestivos nesse alinhamento, pois a alteridade circundante promove a reflexividade na condição do próprio estranhamento como elemento de desnuclearização de um confortável/pessimista “centro" gravitacional contextualmente estabelecido da identidade. 
(1977), “contenção e excessos". Direta e indiretamente, as diásporas representam a construção de novos enigmas de distanciamento em condições de significados que podem ser feitos, como se refere à imagem cliffordiana, em políticas de representação "utópicas e distópicas" que se experienciam em novas possibilidades de "contato" no âmbito da zona de emergência da mobilidade transcultural.

Esse aspecto é o que mais gostaríamos de analisar nas referências de um "texto filmico" sobre os processos narrativos migratórios como composições também à margem dos jogos de força das alteridades referenciais. Jogos de força em situação de enredamento com o próprio discurso em suas relações de indefinibilidade e anonimato e também como "itens" transculturais que desenvolvem muito do sentido ambivalente (da palavra) pertencimento.

\section{Uma vantagem transcultural aos espetáculos culturais: um olhar sobre um "filme migratório" na perspectiva da identidade peregrina}

A seguir observaremos um filme migratório que pode ser lido dentro das perspectivas diaspóricas em situação de estranhamento. 14 Kilómetros é uma produção hispânica de 2007 que, conforme aponta Monterde (2008), mais do que um retrato da imigração à Espanha, é um filme espanhol sobre o drama da emigração sub-sahariana em geral, expressando as dificuldades da longa travessia do deserto através de Mali, Niger, Argélia e Marrocos. Escrita e dirigida por Gerardo Olivares, expõe a história de dois jovens e seu périplo pelo continente africano até a chegada aos 14 quilômetros que separam o continente da Europa. Centrada na dimensão relacional das identidades e pensando os projetos migratórios desde a origem, é um filme que, com certa proximidade a um estilo documental que recupera os processos de deslocamento desde a contemplação da ideia da partida à forçabilidade original do distanciamento, busca pensar as ambivalências dos deslocamentos humanos em suas questões individuais e coletivas. A noção da inadaptação e da dificuldade de levar a cabo os projetos de vida no âmbito cultural de origem, e a situação precária da involução identitária, mais do que as dificuldades econômicas, tecem a trama dos dois protagonistas principais que contemplam a experiência da transição humana em uma realidade que estabelece dificuldades estruturantes para dar seguimento ao projeto de vida inicial, influindo no ponto de inevitabilidade do momento decisório da partida. Posteriormente, a multiplicidade de obstáculos e alterações significativas na capacidade de utilizar a experiência comunal anterior como fortaleza para o projeto de vida é mostrada com a visão do itinerário como impeditivo em si da obtenção da liberdade.

A experiência do distanciamento promove, nos dois empreendedores da jornada, por diferentes questões pessoais, a noção de uma identidade peregrina que se processa nas modalidades de trânsito e pertencimento, disponibilizando a noção autocriativa de gerir-se a partir do anonimato. O filme traz a figura principal de Buba, africano de Niger que, com habilidades futebolísticas, é estimulado pelo treinador e pelo irmão mais velho a provar a sorte na Europa, em algum clube de futebol profissional. Seu pequeno quarto 
é cheio de pôsteres com fotos de jogadores famosos, e o irmão o impulsa à jornada migratória pela discrepância de realidades e o fim prematuro da condição de jogador pela idade avançada. O filme mostra a reflexão do protagonista em um diálogo central, pois a peregrinação é considerada perigosa e o processo de deslocamento não é lido como fácil pelo protagonista, mas, mais do que o imaginário e a possibilidade de sucesso em outra paisagem, são etapas sucessivas ao contexto amplamente desprivilegiado de onde se parte. A experiência individual e nuclear da sensação de que poderia conseguir mais do que a realidade apresenta torna o projeto de trânsito uma condição inevitável da continuidade da individuação. Nesse contexto, utiliza o que a teoria migratória (Mateos, 2004) expõe sobre o mercado de sonhos da experiência migrante e a realidade social que não consegue dar conta de absorver minimamente os projetos individuais da construção de significados de vida. O recrutamento pessoal para a prática do deslocamento tem menos a ver com a mobilidade social ascendente do que com a lógica da impermeabilidade seletiva de uma situação de existência que trata as promessas de prosperidade como ceifadas antes de poderem observar suas condições sociológicas. Em uma visão popular, escapa-se da realidade social porque há necessidades não satisfeitas, mas a experiência diaspórica, conforme retratado em 14 Kilómetros, inscreve-se, em última instância, no conhecimento que a natureza desse processo está profundamente imbricada com a ação individual, ato decisório que prescinde da metáfora do desgarramento e observa a peregrinação como a tomada de decisão de consciência de uma individuação necessária.

Nesse sentido, o registro de que os migrantes se transladam em busca de liberdade e continuidade da experiência identitária surge com o tratamento do discurso filmico a partir do relativismo da lógica econômica para uma percepção de que o mais importante é a continuidade da mudança individual como parte fundamental do pertencimento ao projeto de vida ${ }^{5}$. O filme é sociologicamente relevante porque não desfragmenta o processo migratório em partes desiguais da condição diaspórica, o que aconteceria se focalizasse exclusivamente o território do pertencimento à noção de expectativas, ou se observasse apenas o processo de chegada e as dificuldades de integração. É interessante porque arrisca em observar as condições de origem-trajeto-chegada como um movimento significativo de busca por questionamentos que tem a ver com a representação de si e da realidade a ser feita a partir de olhos sempre distante de onde recebem o primeiro imaginário. Nesse sentido, é um filme migratório que enfatiza os sucessivos paradigmáticos da própria condição diaspórica, uma absorvência na estrada que mostra o árduo caminho de conquista de um novo sentimento de coerência para um sentido biográfico que, por isso mesmo, revela a necessidade de distanciar-se de uma situação psíquica dolorosa. A contextualização da realidade social apresentada pela temática diaspórica evita que o filme

Isso fica implícito quando, diante da advertência sobre o alto custo e as dificuldades da jornada, o irmão de Buba explica que poderiam vender a moto e reunir a quantidade necessária para a viagem e o pagamento dos intermediários. Mesmo que consciente do tamanho da empresa, Buba é lançado à experiência migrante porque a história de vida precisa ser descontextualizada para poder seguir representando-se a si mesma. 
naturalize o processo de tomada de decisão da experiência migrante, fundamentalmente na reflexividade do personagem central, Buba, e de Violeta, que o acompanha em parte da narrativa, quando ambos pensam sobre a situação do deslocamento como uma forma de aplacar o sentimento de desamparo aberto pela incoerência entre a situação de vida e as expectativas da identidade. A opção narrativa por uma figura central, um jovem sub-sahariano com bom potencial futebolístico, acompanhado em parte da estrutura filmica por uma jovem mulher com um casamento arranjado, além de uma figura de apoio (o irmão mais velho de Buba, Mukela, que o filme apresenta como algo experiente na jornada), é interessante porque desconstrói o estereótipo do imigrante masculino, economicamente desprivilegiado e socialmente anulado (o filme sugere que a empresa migratória é acessível aos dois protagonistas mais do que a realidade de onde partem).

Nesse aspecto, certo esquematismo sociológico sugerido logo no início é rapidamente desconstruído pela racionalização da experiência da frustração quanto à realidade social que faz emergir o lócus da desidentificação. Não é apenas esta que, miserável e impossível de dar sequência à continuidade do projeto biográfico, surge como fator impulsor da diáspora. Mas é o próprio processo de fronteirização da identidade que precisa ser constantemente revisto, ampliado no incômodo psicológico inicial com a perspectiva de uma vida sem o seguimento da individuação. Tanto Buba como Violeta podem escolher não emigrar, mas preferem conscientemente a partida, porque estão formados por laços históricos e culturais que produzem a única condição possível de reversibilidade na busca por um fim em si mesmo. A decisão da partida tem características e pano de fundo social, mas a disposição para a jornada faz das transformações diaspóricas o limite da condição da biografia que precisa encontrar seu ponto de concentração e dispersão, necessário para conseguir ressignificar a imagem da relatividade da identidade e o limite constantemente aberto da identificação. A jornada, em si, é uma "zona de contato" que dispõe aos aspectos mais dialetizáveis da identidade sem perder de vista a metáfora transcultural do sentimento de abandono pela perda específica da estrutura da partida e pelo isolamento da vivência cotidiana em uma situação diferenciadora da origem constantemente lembrada.

Nessa linha de construção, semelhante aos filmes com proposta narrativa próxima ao documental, 14 Kilómetros tem um projeto discursivo-imagístico que o alinha com os filmes de temática migratória africana (Bakari, 1996). Mas o filme não esquece a possibilidade de observar a transcendência da mensagem do itinerário como "zona de contato", em que o impacto das paisagens extensas do deserto são contrastadas com a biografia dos personagens. Há, também, o elemento irônico ao institucionalizar-se a representação da fronteira em lugares que respondem muito mais a imaginários pseudonacionais que a identificação territorial propriamente estabelece ${ }^{6}$.A estética do trânsito e do espaçamento absurdo representam "não lugares" (Augé, 2005) e devires que abraçam uma proposta

6 Por exemplo, na sequência em que um solitário oficial de aduana interrompe lentamente a marcha de um caminhão carregado de pessoas em deslocamento para exigir "papéis", suporte formalista e instável em um campo que contam o tratamento condicional das propinas mais do que a legalização nominal. 
filmica em que o fenômeno da transposição de itinerários situa os sujeitos como adversários da paisagem, mítica pela contemplação e terrível pelo anonimato ${ }^{7}$. A possibilidade da anulação da identidade, não obstante, está muito mais próxima no contato com os humanos do que com a enormidade transterritorial. Esse paradoxo define a experiência migratória e, de certa maneira, define o próprio filme: quanto mais se anseia a biografia individual, mais o território de origem é acionado para desprezar valores de mobilidade e anular um sentido comunitário. $O$ filme cria um ponto de tensão não resolvido que é inteligente ao não esperar, portanto, que a aspiração individual "vença" a dificuldade sociológica. O caráter de sorte, e o "sucesso" da empresa migrante, está relacionado com a sugestão de que a continuidade das dificuldades segue, ou se tornam mais abissais, com o ponto de inflexão final: o olhar judicializante, mas compassivo, do guarda civil espanhol que não observa, ou observa menos, os dois novos imigrantes ilegais em solo europeu.

A imagem do transporte, transcendência, transposição, representa a confiança em um cinema que faz leituras da sobrevivência inseridas no contexto amplo da migração como um fenômeno sociocultural, mas também como elemento diacrítico na portabilidade da errância como substrato simbólico da narrativa da viagem. Nesse sentido, a discussão de Clifford (1999) da comunitas do processo de mobilidade assume as narrativas em trânsito como processos de reposicionamento dos sujeitos sociais que, lançados ao oculto dos "não lugares", podem reorganizar a experiência do olhar sobre a relação foraneidade-autoctonia, urgidas sobre a experiência fundamental do deslocamento. O campo de deslocamento dispõe, portanto, uma restauração simbólica da condição da anonimidade. A capacidade de atar a biografia à perpetuidade do sonho de individuação, nesse aspecto, alcança a necessidade de conjugar as experiências transterritoriais com as representações imagéticas da condição do pertencimento.

O filme apresenta a lógica dessa execução em um momento-chave: quando o protagonista principal, juntamente com a jovem que o acompanha em parte da diegese, desfalecidos em um ponto longínquo do deserto, são salvos por nômades tuaregues, sinônimos absolutos do desterro e da sobrevivência errante. Sendo o deserto a pletórica de um "não lugar", animicamente desconfigurativo, a questão da identidade é levantada no diálogo de Buba com um dos chefes tribais: ao ser questionado sobre a vida nômade, o chefe diz que a condição de existência no deserto é o ponto de apoio da própria identidade, e que a sensação de lar está na interpedendência sujeitos-lugar de trânsito. O fato de serem salvos por inanição em um ponto profundo do deserto revela, comparativamente, outra faceta dos processos migratórios: o judicialismo fundamental lançado aos diaspóricos pelas culturas de absorvência europeias em contraste com a amabilidade e o cuidado proferido pelos nômades do deserto. A proteção e o restabelecimento de Buba eVioleta são feitos pelos tuaregues, que tratam os forâneos com uma ética compassiva e amigável. O discurso filmico, nesse modelo, conjuga-se com as teorias migratórias quando explora as relações entre as escolhas narrativas e a identidade na estrada, focalizando as dinâmicas intercultu- 
rais entre as historicidades móveis subjacentes às diversas situações de recepção imigrante. Em nenhum aspecto, o filme está preocupado em impor uma lógica nós-outros sem questionar o efeito das consequências sociais, biográficas e imagéticas dos processos de transposição territorial. A imagem da experiência do deslocamento como condição sine qua non da construção dos itinerários transculturais africanos frisa o movimento significativo de índices de significado que constroem suas identidades a partir de "zonas de contato/emergência" abertas pela globalização circundante que tem significativo impacto nas dinâmicas da alteridade. Como pontua Bensalah (2005), as transformações biográficas ocorridas ao longo do périplo migratório - no caso de 14 Kilómetros, os dez meses em movimento dos protagonistas ao longo do continente africano -, apontam para a organização da experiência do estrangeirismo como tentativa de equilíbrio da desestruturação histórica entre sujeito de pertencimento, imaginário de escolha e oportunidade de vida. ${ }^{8}$

Como o filme apresenta, as migrações têm uma dupla dimensão de elementos coletivos e individuais, assim como sociais e afetivos, e o fato coletivo de a experiência do itinerário ser uma saída para o desenvolvimento pessoal inscreve a importância das trajetórias individuais como experiências singulares através da irrupção de fluxos históricos desvantajosos. A perspectiva da mudança de vida aberta pela mobilidade revela que a força do imaginário simbólico-positivo, quando associado ao universo de destino, é muito mais forte do que as seguidas dificuldades do deslocamento. Nesse campo, por si só, as teorias migratórias (Nash, 2005; Portes, 2010; Mateos, 2009) explicam que o próprio ato emigrante tem a ver com a coragem de não esmorecer diante da situação desprivilegiada e que a indústria da fabricação dos sonhos de mobilidade é um processo que frutifica nas sociedades lidas como periféricas ${ }^{9}$.

A construção posicional do discurso filmico em 14 Kilómetros refere-se, dentro dessas linhas argumentativas, naquilo que Clifford (1999) aponta como o principal interrogante e que também norteia esse trabalho: "De que forma os discursos da diáspora representam experiências de deslocamento, de construção de lares distantes da terra de origem? ${ }^{10 "}$ (Clifford, 1999, p. 299, tradução minha). Tal questionamento se debruça sobre as visões da diáspora na historiografia do sentido biográfico do pertencimento em um horizonte feito de mutações migrantes, lugar de experiências que "recusam, deslocam ou marginalizam"11 (Clifford, 1999, p. 299, tradução minha) a identidade peregrina.

O filme traduz com solvência e humanização a leitura sobre a força da narrativa viajeira, porque quer olhar substancialmente a origem e a travessia como processos de construção de significados que, mais do que uma atração sociológica, dão voz, sentido e protagonismo ao emigrante. Desloca-se desde um contexto coletivo de experiência para

8 Nesse caso, aquilo que Nair (2007) argumenta sobre o desequilíbrio estrutural entre sujeitos periféricos e as sociedades de chegada, com maiores possibilidades de dar sequência à regularidade da aspiração de significados.

9 Composta no próprio silogismo: “vou melhorar”.

10 Texto original em espanhol.

11 Texto original em espanhol. 
o itinerário individual refeito pelo anonimato da viagem diaspórica. Nessa condição, o filme expõe como a mudança de localização desfragmenta a identidade peregrina, mas mantém a força do ideário simbólico-imagístico enquanto ele segue sendo produtor de uma economia psíquica menos da advertência do que da disposição para um destino mais digno. Nesse sentido, a história de Buba dá forma a uma percepção da migração como narrativa de ambivalência, porque força o sujeito a lidar com os aspectos não diacríticos da identidade, envolvendo-o em novas possibilidades identificatórias. Os discursos emergentes nas diásporas migrantes, como a perspectiva cliffordiana vista em 14 Kilómetros reflete, tornam-se, dessa maneira, um potencial tanto para a possível desidentificação como para a criação biográfica. A fala do protagonista é limítrofe nessa condição de estranhamento que ele, a partir do redirecionamento da história de vida, estabelece como um meio de autoconhecimento e de gestação da identidade como consequência do diasporismo.

Os discursos diaspóricos, não obstante, são advertências de uma possibilidade anterior que, através do périplo, recriam e oferecem, segundo Clifford (1999, p. 270, tradução nossa), "recursos para os 'pós-colonialismos' emergentes". E, nesse sentido, 14 Kilómetros é um filme de sensibilidade emergente que observa a identidade em trânsito sentida como um meio de negociar com estruturas limitadas e anteriormente definidas pela condição histórico-social desfavorável. A articulação da identidade peregrina, realizada em um processo que leva em conta a biografia pessoal, organiza à experiência da identidade a ser construída de maneira situacional, atuando como uma resposta simbolicamente resistente a determinada conjuntura de desvalorização das histórias de vida.

As feridas psíquicas da violência da amputação do imaginário, extraído o mais precocemente da realidade sociológica, são refeitas pelo novo conceito de identidade diaspórica, inscrita na estrutura do deslocamento e na percepção do trânsito como transposição de horizontes (territoriais, fronteiriços, impeditivos). Os lugares de partida e de chegada, em 14 Kilómetros, são, nesse sentido, menos importantes que a travessia em si. A diáspora serve de mapa para o movimento de desidentificação dos epifenômenos territoriais. E o relato biográfico da composição filmica ensaia a possibilidade de, em deslocamento, enfatizar aquilo que se entende como referência na dinâmica existencial. Ou seja, a experiência migratória, nesse âmbito, pode ser lida como uma experiência de fronteira, que, através de "zonas de contato", reatualiza o sentido de autonomia da circulação cultural, ainda que a frequência e a disponibilidade para tal artifício estejam sempre condicionadas ao considerável emblema de incorporação.

Como a alteridade também é uma condição do esquecimento produzido, para a personagem de $\mathrm{Buba}^{12}$, a travessia se torna ainda mais significativa para anular o estigma do pertencimento que produziu um imaginário solto e uma existência social impeditiva.

12 Buba representa diegeticamente a possibilidade de perceber a violência das narrativas hegemônicas (futebol, juventude, empreendorismo individual) que sedimentam a visualidade das sociedades de recepção como ilusoriamente abertas ao deslocamento de jovens migrantes; a figura do protagonista masculino expõe a força de atração dos sistemas imaginários no "efeito chamado" dos jovens africanos. 
O estranhamento, como pontua Taussig (1992), pode ter um alcance comparativo e um efeito sintético muito mais interessante do que a articulação da leitura do lado negativo do vínculo. Tão redundante como necessária, a circulação da identidade pode ser gestada a partir do domínio da biografia e da tensão criativa entre aquilo que estamos chamando de historicidades móveis e o que pode ser entendido como imagéticas de culturas de recepção. Na prática, as escolhas desidentificatórias e peregrinas dos filmes de travessia, como 14 Kilómetros, são instâncias que dimensionam a ideia cliffordiana de "zona de contato" como a possibilidade de tomada de decisão sobre a natureza da diversidade.

No filme de Gerardo Olivares, é a relação prévia imaginário-cultura que torna possível e favorável o processo de relativismo espacial em uma disposição em romper com a condição de origem. Supondo que essa dinâmica não é consequência totalmente direta do trânsito, pois ele não foi forçado apenas pela negatividade sociocultural, mas pela intenção de teledirigir o destino, o movimento de desidentificar-se pode sim ser entendido como uma qualidade semântica indexada ao processo de mobilidade transterritorial ${ }^{13}$.

A relação sociedade-biografia, pensada na imagem do migrante em busca da relativização espacial, completa-se pela experiência da transição humana em uma realidade que faz a "identidade peregrina" um meio de experiência significativa da sensação de maior domínio da "emergência" do discurso pós-colonial. Como reflete Brooks (1984), as narrativas se direcionam a uma intenção discursiva que, dispersas pela historiografia, conduzem a uma redefinição da identidade individual no âmbito conciso do distanciamento. Se Buba é desfavorecido pela sociedade de partida, ele também está possivelmente mais preparado para obter, com a anonimidade, a característica transformatória do reconhecimento do próprio destino. A vantagem do filme é justamente dispor que a transculturalidade possa ser um item imprescindível da crítica à ideia da metaforização cultural. A noção de pertencimento está, portanto, não nas margens (Derrida, 1991), mas na capacidade de transformações que são suficientes para dar conta de um projeto de vida que, de outra forma, não poderia manifestar-se além do escopo da memória e além da indumentária da localidade. A reciprocidade identidade peregrina e imaginário da travessia promove então a possibilidade de se pensar a relação cultura-subjetividade na dinâmica do migrante que precisará negociar (emergir, adensar, negar), futuramente, as características da cultura em que se vê lançado e que carrega idealmente.

O material de reflexão comparativo "Nós-Outros" produz arbitrariedades que o trânsito cultural observa como meio substantivo de aderência metafórica. A identidade peregrina torna possível rever os aspectos mais acessórios da construção da imagem da cultura de projeção e faz viável a ideia da crítica reflexiva em relação à composição a ser encontrada. Nas margens da metáfora, como escreve Derrida (1992), os discursos migrantes podem revelar uma leitura bastante significativa daquilo que estamos explorando como a experiência diaspórica da autoctonia no imaginário-cultura cinematográfico.

13 Queremos nos perguntar aqui: o quão "forçada" é a prática irrestrita do distanciamento quando ele serve de característica de apoio à renegociação, através do anonimato, da identidade na estrada? 
No filme 14 Kilómetros, a identidade peregrina possibilita a experiência mais direta de confronto com as características lidas como negativas e excessivamente críticas do "espetáculo" cultural visto a partir de dentro e, concorrentemente, da anulação daqueles aspectos considerados mais problemáticos dessa coletividade anterior. Na estrada, os discursos diaspóricos retomam a ideia de Yúdice (2004) de cultura como projeto de encadeamento de forças que se tornam reagrupadas, refeitas, relidas e tensionadas quando se cruzam. A partir de seus portadores diaspóricos, a memória cultural dos migrantes elabora a natureza verdadeiramente evenemencial da situação do deslocamento, que consegue, em certa medida, dispor os processos de significação nos lugares em que eles estão mais abertos e talvez mais propícios à capacidade de permuta cultural.

Alguns filmes com temática migratória enfocada na travessia, como 14 Kilómetros, nesse sentido, recuperam a relação de consciência da peregrinação a partir da anulação, no entrecruzamento, da visão da aderência ao projeto colaborativo em todo âmbito cultural estabelecido previamente. Ao mesmo tempo, insere, através da fronteira, a restauração possível do emigrante em sua capacidade, antes remota, de maior domínio da leitura das perspectivas daquilo que chamaremos de "autonomia da falseabilidade". Falsificação que dispõe um projeto de vida retomado a partir da condição da exterioridade, lido como renegociação conforme a visão da cultura de recepção (especialmente em seus conteúdos dispersados na metáfora da espetacularidade). Como escreve Hall (2003), nas margens, nas situações fronteiriças, o trânsito cultural consegue fazer manter a ideia de um "centro original" que pode ser apoiado em uma ideia de desejo de "regresso final". Nossa análise é que 14 Kilómetros redefine a relação, porque está perifericamente não "nas margens" da concepção do imaginário cultural, mas no centro da situação do estranhamento que permite, justamente pela transculturalidade, utilizar e conservar a "memória da metáfora" como signo de pertencimento obstacularizado na origem.

Ser diluído na metáfora da representação significa não querer expor a vulnerabilidade para os fins de uma tendência que tem a ver com a territorialização absoluta daquilo que deveria claudicar a experiência: as culturas transnacionais não perdem o sentido por serem mais ou menos abertas aos novos espaços de representação peregrina, mas é a exclusividade da representação que sofre um abalo.

As políticas de representação no espaço contemporâneo buscam evitar ao máximo as ambiguidades e as fissuras dos discursos com o objetivo de tratar como incomensuráveis os lugares e as poéticas das vozes nas "zonas de contato". O mais explícito da identidade é um vazio que somente se percebe quando ela é colocada em jogo, ou seja, quando as experiências relacionais subvertem as práticas de dominação e controle das hegemonias territoriais. O mito da consecução desse lugar de imbricações mostra-se quando a vida, dentro da portabilidade da imagem, já não atinge o núcleo de orientação destinatário e se instaura uma vantagem, sublime porque seguidamente levantada pela ocupação da consciência, de que as edificações étnicas podem e devem ser soterradas pela memória. 


\section{Esboço final: uma dialética contemporânea da perda do espaço como transposição de indiferenças}

O cinema pós-colonial e "migratório", conforme analisa Foster (1999), é um cinema que nasce de uma perspectiva intercultural e intersubjetiva e que, sobretudo, tem a vantagem de pensar a experiência da transição humana realizada em um âmbito que observa as identidades como possivelmente mais posicionais e contestadas do que a certeza de uma ordem coletiva produzida pela territorialização exclusiva do espaço (ainda que espaços fictícios, alegóricos, fabulativos). A dinâmica de 14 kilômetros inscreve-se na percepção de que o efeito do deslocamento age sobre a metáfora da reavaliação e da incorporação de significados, e a natureza desse deslocamento atinge indivíduos e coletividades de modo heterogêneo. Isso não significa que a narratividade dos filmes de compleição profunda diante do tema da transição de fronteiras (míticas, imaginadas, multi e pluridimensionais) seja uma narratividade que opta pelos processos de pluralidade de fluxos, sem pensar os grupos e pessoas que se deslocam e que recebem o lado mais contundente da metáfora da transição: o sentimento de uma terra ou de um lar que é deixado para trás, porque significa impedimento ou porque significa insuficiência.

Nesse aspecto, a globalização do imaginário e a iminência da perda dele a todo instante, nos termos que as ciências sociais problematizam (Canclini, 2012), tem a ver com o paradigma de um mundo enfermo de si, que obriga os sujeitos à condição da exterioridade para poderem, minimamente, contornarem uma desfamiliarização com o entorno que é o ponto de partida da reminiscência do que somos: um fragmento em perpétuo estado de estranhamento e, ainda assim, sem nunca se sentir completamente em casa e sem dispor de sedimentação para pensá-la como ausente do lugar onde se encontra.

A cinematografia contemporânea, como aponta Bordwell (2008), tem sido mais cuidadosa em pensar esses sujeitos em políticas de representação que não apelam para o binômio foraneidade-autoctonia, simplesmente, desprovidas da experiência fundamental do posicionamento relativo. Faz uma leitura mais ambiciosa ao pensar que os sujeitos e as culturas são provavelmente mais indecisos, desconhecidos e plurais do que parecem. À luz desse debate, as identidades focalizadas pela busca por uma situação mais condizente com um cenário de intensos cruzamentos organizam melhor a experiência filmica dentro de um lócus em que as culturas e as sociedades são vistas como um processo aberto. Sobretudo, mais dispostas e autocríticas no sentido de que os deslocamentos humanos são realizados por sujeitos que têm suas historicidades mobilizadas em um número muito mais amplo e, repetidamente, irrestrito, que dissolve a imagem da experiência da incorporação como um processo intersubjetivamente controlável. Para resumir essa abordagem, 14 kilômetros, conjuga prática dos itinerários transculturais a partir de zonas de contato abertas pela globalização circundante e busca um maior valor à interpretação da experiência do deslocamento desde uma ambiguidade processual e simultânea que vê a imagem da fronteira como uma necessidade de adoção de perspectivas interculturais. Isso não significa que dada ordem ficcional que entenda as características simbióticas e variavelmente 
constitutivas do pertencer, como escreve Bordwell (1996), compense a falta de atividade em um cinema que é, sobretudo, uma aposta, mais do que contemplativa, da esfera da alteridade no jogo que ela conclusivamente não está nunca terminada.

O olhar cinematográfico ao estranhamento, sub judice, tende, muitas vezes, a psicologizar demais os processos migratórios (França, 2007) e reduzir as escolhas migrantes como operações de identificações que são produtos da imagem de alguém que previamente tem escolha, ou que já é produto de uma escolha anterior. Na base dessa interpretação está o pensamento de que as identidades buscam, sempre nos termos delas mesmas, determinado distanciamento de uma posição histórica que lê o passado como uma nomenclatura de sucessivas faltas estruturantes. Isso não significa, obviamente, que o alcance heurístico dessa interpretação tenha a ver com o dado mais paradigmático de uma cultura do adiamento do imaginário, coisa que o cinema, como pontua Monterde (2008), vem historicamente produzindo a fim de reduzir e validar as contínuas disparidades entre o que é representado e o que pode ser retido como identificação dentro da representação. É necessário, por isso mesmo, sempre lembrar que as vivências intersubjetivas são também relações de força e, como tal, dependem de amplas disposições de hegemonias e assimetrias que circulam a imagem da transfronteirização. As identidades retratadas em muitos dos filmes com um viés migratório, no espaço contemporâneo, não negam o passado como um local difícil de ser simultâneo com a lógica do desprendimento e com a absorção da diferença. As identidades de 14 kilômetros preferem fugir dos binarismos (sociedades de impulsão-recepção, lógica de forças econômicas push-pull, etc.), porque se avaliam na preocupação em desenvolver a sensibilidade intercultural para poder repensar o pertencimento e a identificação (e o acesso a estes) entre sociedades e subjetividades.

Conforme o jogo metafórico da cultura do desprendimento, a experimentação está em ir ao limite do esforço de pensar as narrativas "na estrada" como somente uma opção por partilhar melhor a estrutura da significação em um lugar que não é, comumente, o âmbito do enraizamento inicial - mesmo porque a conformação subjetividade-cultura no entorno, interna e externamente, é lida usualmente como convenção maior a ser respeitada. Dar suporte e assistência à adaptação cultural, ver as identidades naquilo que elas têm de mais fronteiriças e mais condizentes com a natureza das identificações, tem sido a preocupação de cinematografias como as de Emir Kusturica, Abbas Kiarostami, Mathieu Kassovitz, Ken Loach, Gerardo Olivares, Rachid Bouchared, entre muitos outros.

Mas a pergunta que ainda mais incomoda a maior parte das leituras contemporâneas sobre os fluxos migratórios no cinema talvez seja a seguinte: por que, historicamente, o cinema tem tamanha dificuldade em trabalhar o sentido do pertencimento sem sobrecarregá-lo em imagens culturalmente essencialistas? A resposta provavelmente está naquilo que Monterde (2008) escreve sobre as condições mesmas de compactação do universo filmico-narrativo: porque o cinema trata o pertencimento e as relações culturais como variáveis independentes.

Nesse sentido, como as identificações pertencem à ordem do imaginário (Burawoy, 1991, p. 17), sendo "esforços fantasmagóricos de alinhamento, de lealdade, de coabita- 
ções ambíguas e intercorporais", o cinema tende a reduzir o esforço da complexidade da identidade ao pensar os sujeitos migrantes dentro de séries de acontecimentos lidos como naturais. A maior dificuldade dessa interpretação, como aponta Keith Moxley (2005), é que os deslocamentos são lidos a partir de duas premissas incorretas: (1) apenas os sujeitos emigram e as sociedades absorvem; (2) os conjuntos de representações primeiro respondem a psicologismos e depois à história cultural.

Nesse ponto, esquece-se, como reflete Canclini (2012), da dialética fundamental da simultaneidade sujeito-posição cultural, uma vez que a sociedade participa da constituição da identificação e que a partida tem a ver com a crença numa estabilidade cultural outra que perde significância no momento exato que aprende de si mesma. E, leia-se, "aprender" está constitutivamente em relação ao deslocar-se.

As cinematografias contemporâneas que cuidam desses processos escapam mais dessas definições sistematicamente encerradas em si mesmas, porque, como pontua Zizek (2013), sentidas vezes evitam promover uma inculcação de estereótipos sem previamente lançá-los à margem do pensamento reflexivo. A visão de que as culturas emergem de interações adaptativas, a partir de elementos partilhados e, sobretudo, de que são transmitidas através do tempo e das gerações, responde por um efeito que tem a ver com a preocupação filmica em pensar as adaptações e as estratégias aculturativas não como inabilidades sociais ou subjetivas, mas como entrelaçamentos possíveis nas diferentes zonas de contato. A interseção destas está estabelecida na percepção, ainda maior, de que as identidades vivem e se nutrem de correlações parciais, e que essas parcialidades são inerentes ao jogo de busca por estabilidades que não podem ser mediadas unicamente entre a subjetividade e a autoctonia relativos ao "lugar" e ao "não lugar".

A dialética do que é simultâneo nessas conformações revela como, "nas margens da metáfora", a transculturalidade pode ser pensada como "zonas de contato" que revelam, ou fazem revelar, os processos de trânsito como inegavelmente sucessivos de uma abordagem da codependência: o cinema que revela a transição e focaliza as margens do desenvolvimento adaptativo, e os filmes que tratam da dialética da variabilidade do cruzamento de territórios. Esses dois cinemas, como lugares objetivos em que os imaginários também se desmontam, ganha validade porque estimulam e desenvolvem uma estética da percepção da vulnerabildade. Ou seja, a elaboração da transformação transcultural que está imediatamente salvaguardada nas possibilidades de convivência e nas suas implicações sempre dificeis. A vocação sui generis de filmes concertados com uma proposta transfronteiriça ${ }^{14}$ pensa os processos de deslocamento como visibilidades móveis que analisam a teia de dificuldades enfrentadas pelos sujeitos e grupos em situação de trânsito, alçados ao contato intercultural nas experiências que podem ser, ao mesmo tempo, profundas, patológicas e disruptivas para o indivíduo e pessoas do entorno.

Como pontua Michael Cole (1996), o estresse comumente associado às experiências de desterritorialização não necessariamente é negativo. A ordem do estímulo, a expectati-

14 Tomemos, por exemplo, algumas propostas filmicas lançadas no ano passado, de diretores como Kim Nguyen, Cristian Mungiu, Ulrich Seidl, entre outros. 
va de transformação e da própria experiência podem influir positivamente nos contextos de origem, recepção e retorno dos diversos lugares readaptativos onde há hibernação, negociação, continuidade e reconfecção dos processos de identidade. Os movimentos transfronteiriços tendem a desestabilizar as prerrogativas culturais conhecidas. Dissipam as sedimentações inerentes ao conhecimento psicológico do lugar de origem e fazem dos sujeitos posicionalmente mais abertos à disposição relacional. O cinema das identidades híbridas, os filmes que processam o significado sem essencializar perspectivas tratam das correlações entre a fabricação de imaginários no contexto das relações culturais e sociais e têm conseguido diminuir, como lembra França (2007), o lugar em que são desenhadas a cultura dos estereótipos e as criações culturais nomeadas das representações dos sujeitos e grupos "em deslocamento".

Não faz sentido desconsiderar um cinema crescentemente não dicotômico que enfatiza, antes de tudo, a operação diaspórica como instância em que as identidades em trânsito são lidas como “zonas de contato”. Não faz sentido, sobretudo, porque a contínua possibilidade de rupturas transforma seus sujeitos que demarcam as fronteiras quando elas mais estão submersas ou quando mais se apagam as margens em que são lidas como hegemônicas.

"Na viagem, podemos experimentar, ainda que de forma limitada, as delícias e as inseguranças da instabilidade e da precariedade da identidade" (Stuart Hall, 2003)

\section{Referências}

AUGÉ, M. Não-lugares: introdução a uma Antropologia da Supermodernidade. Campinas: Papirus, 2005

BAKARI, Imruh-Cham. African experiences of cinema. Londres: British Film Institute, 1996.

BALLESTEROS, Isolina. Cine (ins)urgente: textos filmicos y contextos culturales de la España posfranquista. Madrid: Editorial Fundamentos, 2001.

BECK, Ulrich. What is globalisation? Cambridge: Polity Press, 2004.

BENSALAH, Mohamed. Cinéma en Mediterranée: une passarelle entre cultures. Paris: Edisud, 2005.

BORDWELL, David. Narration in the fiction film. Madison: University of Wisconsin Press, 1996. Poetics of cinema. Nova York: Routledge, 2008.

BROOKS, Peter. Reading for the plot: design and intention in narrative. Nova York: Knopf, 1984.

BURAWOY, Michael. Ethnography unbound: power and resistance in the modern metropolis. Berkeley: University of California Press, 1991.

CANCLINI, Nestor Garcia. A globalização imaginada. São Paulo: Iluminuras, 2001. A sociedade sem relato: antropologia e estética da iminência. São Paulo: Edusp, 2012.

CANTWELL, Robert. Ethnomimesis: folklife and the representation of culture. Chapel Hill: University of North Carolina Press, 1993.

CLIFFORD, James. Dilemas da cultura: antropología, literatura y arte en la perspectiva posmoderna. Barcelona: Gedisa, 1999. 
Routes: travel and translation in the late Twentieth Century. Cambridge, Massachusetts: Harvard University Press, 1977.

COLE, Michael. Psicología cultural. Madrid: Morata, 1996.

DERRIDA, Jacques. Dissemination. Chicago: University of Chicago Press, 1992.

Positions. Chicago: University of Chicago Press, 1991.

FOSTER, Gwendolyn. Captives bodies: postcolonial subjectivity in cinema. Albany: State University of New York Press, 1999.

FRANÇA, Andrea. Novos errantes do cinema político contemporâneo. In: BENTES, Ivana. Ecos do cinema de Lumiére ao digital. Rio de Janeiro: UFRJ, 2007.

HALL, S. A identidade cultural na pós-modernidade. Rio de Janeiro: DP\&A Editora, 2003.

MATEOS, N. R. El debate sobre la globalización. Barcelona: Editorial Bellaterra, 2009.

. Una invitación a la Sociología de las Migraciones. Barcelona: Editorial Bellaterra, 2004.

MONTERDE, José Enrique. El sueño de Europa: cine y migraciones desde el sur. Andalucia: Junta de Andalucia, 2008.

MOXLEY, Keith. Estética de la cultura visual en el momento de la globalización. In: BREA, José Luis (Ed.). La epistemología de la visualidad en la era de la globalización. Madrid: Akal, 2005.

NAIR, Sami. La Europa mestiza: inmigración, ciudadania, codesarollo. Madrid: Galaxia Gutemberg, 2010. . Y vendrán... Las migraciones en tiempos hostiles. Barcelona: Bronce, 2007.

NASH, Mary. Inmigrantes en nuestro espejo: inmigración y discurso periodístico en la prensa española.Barcelona: Icaria Antrazyt, 2005.

PORTES,A.A Cross-Atlantic dialogue: the progress of research and theory in the study of international migration. International Migration Review, n. 38, p. 828-851.

ROCCO, R.; SELGAS, F. Transnationalism: issues and perspectives. Madrid: Editorial Complutense, 2005.

STAM, Robert. Film theory. Massachusetts: Blackwell Publishers, 2002.

STOCKING, George. Observers observed: essays on ethnographic fieldwork. Madison: University of Wisconsin Press, 1983.

TAUSSIG, Michael. Mimesis and alterity. New York: Routledge, 1992.

VAN LIEW, Maria. Inmigration films: conventions of (in)visibility in contemporary Spain. In: BECK, Jay; RODRÍGUEZ,Vicente. Contemporary Spanish cinema and genre. Manchester: Manchester University Press, 2008.

YÚDICE, George. A conveniência da cultura. Belo Horizonte: UFMG, 2004.

ZIZEK, Slavoj. Lacrimae rerum: ensayos sobre cine moderno y ciberspacio. Barcelona: Debate, 2013. 


\title{
Transculturality and migration fictions in the identity cinema: diasporic experiences in 14 kilometres
}

\begin{abstract}
This work is part of an interrogation very present in contemporary migration discourses: how do the narratives in transit reposition the subjects in the condition of the look on strangerautochthonous relationship, thought through the fundamental experience of the displacement? The article explores the relationships between narrative choices and identity on the road, focusing on intercultural dynamics between mobile historicities and reception cultures. It develops the image of the experience of displacement as the structural condition of the construction of cultural itineraries from "contact zones / emergency" opened by the surrounding globalization that has significant impact on the dynamics of immigrant alterity. Subsequently, the work expands seeking a review of the essays reflexivity from the emergence of glance at the image of migration places, regarding one filmic discourse on immigrants in cases of transit. The subjectivity-culture relation is thought through the image of the migrant in search of the psychological and communitarian identification in the spatial relativization. The identities observed by the culture of involvement and the relation of forces, hegemonic and asymmetrical, serve as a material for reflection of the comparative reach "We-Other".
\end{abstract}

Keywords: transculturality, migrations discourses, cinema, identity, culture.

\section{Transculturalidad y ficciones migratorias en el cine de la identidad: experiencias diaspóricas en 14 Kilómetros}

\section{Resumen}

El presente trabajo parte de una interrogación bastante presente en los discursos migratorios contemporáneos: ¿cómo las narrativas en tránsito reposicionan a los sujetos en la condición de la mirada sobre la relación foraneidad-autoctonía, pensadas a través de la experiencia fundamental del desplazamiento? El artículo investiga las relaciones entre las opciones de las narrativas y la identidad "na estrada", enfocando las dinámicas interculturales entre las historicidades móviles y las culturas de recepción. Se desarrolla la imagen de la experiencia del desplazamiento como condición estructural de la construcción de los itinerarios culturales a partir de "zonas de contacto / emergencia" abiertas por la globalización circundante, que tiene significativo impacto en las dinámicas de la alteridad inmigrante. Posteriormente, el trabajo analiza la reflexividad ensayística a partir de la emergencia de la mirada sobre la imagen de los lugares migratorios en relación a un discurso fílmico acerca de inmigrantes en procesos de tránsito. La relación subjetividad-cultura es pensada a través de la imagen del migrante en busca de la identificación psicológica y comunitaria en la relativización espacial. Las identidades observadas por la cultura de implicación y la relación de fuerzas, hegemónicas y asimétricas, sirven de material para reflexión del alcance comparativo "Nosotros-Otros".

Palabras clave: transculturalidad, narrativas inmigrantes, cine, identidad, cultura. 
